\title{
Climatic Effects Due to Halogenated Compounds in the Earth's Atmosphere
}

\author{
Wei-Chyung Wang ${ }^{1}$ and Joseph P. Pinto \\ Goddard Institute for Space Studies, New York, NY 10025 \\ YUK LING YUNG \\ California Institute of Technology, Pasadena 91125 \\ (Manuscript received 4 June 1979, in final form 29 August 1979)
}

\begin{abstract}
Using a one-dimensional radiative-convective model, we perform a sensitivity study of the effect of ozone depletion in the stratosphere on the surface temperature. There could be a cooling of the surface temperature by $\sim 0.2 \mathrm{~K}$ due to chlorofluoromethane-induced ozone depletion at steady state (assuming 1973 release rates). This cooling reduces significantly the greenhouse effect due to the presence of chlorofluoromethanes. Carbon tetrafluoride has a strong $\nu_{3}$ band at $7.8 \mu \mathrm{m}$, and the atmospheric greenhouse effect is shown to be 0.07 and $0.12 \mathrm{~K}$ (ppbv) $)^{-1}$ with and without taking into account overlap with $\mathrm{CH}_{4}$ and $\mathrm{N}_{2} \mathrm{O}$ bands. At concentration higher than 1 ppbv, absorption by the $\nu_{3}$ band starts to saturate and the greenhouse effect becomes less efficient.
\end{abstract}

\section{Introduction}

It is well recognized that the thermal structure of the earth's atmosphere is influenced by the presence of trace gases with strong absorption bands in the infrared (Goody, 1964; Manabe and Wetherald, 1967). The main effect of the gases is through the absorption of outgoing thermal radiation in the atmosphere, followed by re-radiation at local temperature. This leads to an increase in the surface temperature, the so-called greenhouse effect. Water vapor effectively blocks thermal emission from the earth's surface except for the window region between 7 and $12 \mu \mathrm{m}$. Carbon dioxide and ozone contribute additional atmospheric opacity at 15 and 9.6 $\mu \mathrm{m}$, respectively. These major trace gases, together with clouds, are primarily responsible for the earth's globally averaged surface temperature being $288 \mathrm{~K}$, some $35 \mathrm{~K}$ warmer than the effective blackbody temperature for the planet.

The atmosphere also contains a number of minor trace gases with strong infrared absorption bands. Despite their small concentrations, they have significant (or potentially significant) effects on the atmosphere's thermal balance (see, e.g., Wang et al., 1976). In this article, we shall concentrate on the halogenated compounds $\mathrm{CFCl}_{3}, \mathrm{CF}_{2} \mathrm{Cl}_{2}$ and $\mathrm{CF}_{4}$. These compounds are currently present in

${ }^{1}$ Present affiliation: Atmospheric and Environmental Research, Inc., Cambridge, MA 02139. the atmosphere with mixing ratios of order $10^{-10}$, with potential for growth to concentrations $>10^{-9}$ due to continued anthropogenic release (see for example NAS, 1976; NASA, 1977; Cicerone, 1979). Ramanathan (1975) pointed out that the presence of a few parts per billion of $\mathrm{CFCl}_{3}$ and $\mathrm{CF}_{2} \mathrm{Cl}_{2}$ in the atmosphere could appreciably warm up the troposphere and the surface. The radiative feedback on the surface temperature due to chlorofluoromethaneinduced ozone depletion was thought to be small. We shall investigate the mechanism and magnitude of this feedback in light of recent photochemical model results on ozone destruction in the lower stratosphere (Yung et al., 1980). In addition, we shall also examine the greenhouse effect due to $\mathrm{CF}_{4}$ which has a strong band at $7.8 \mu \mathrm{m}$.

\section{Description of thermal model}

One-dimensional radiative-convective models which determine the thermal structure of the atmosphere as a result of the balance between the radiative flux and a parameterized convective flux are useful tools for climate studies (see, e.g., Schneider and Dickinson, 1974). Such models include realistic vertical distributions of radiatively important atmospheric constituents, and can be used to examine the roles that these constituents play in determining the global mean temperature structure (Manabe and Wetherald, 1967; Ramanathan, 1976; Wang et al., 1976; Hansen et al., 1978). They are also useful in 
TABle 1a. Comparison of climate sensitivity parameter $\beta$ for one-dimensional radiative-convective models. FCA is fixed cloud altitude, FCT fixed cloud temperature, FAH fixed absolute humidity and FRH fixed relative humidity.

\begin{tabular}{|c|c|c|c|c|}
\hline \multirow[b]{2}{*}{ Model } & \multicolumn{4}{|c|}{$\beta(\mathrm{K})$} \\
\hline & $\begin{array}{l}\text { FAH } \\
\text { and } \\
\text { FCA }\end{array}$ & $\begin{array}{c}\text { FRH } \\
\text { and } \\
\text { FCA }\end{array}$ & $\begin{array}{l}\text { FRH } \\
\text { and } \\
\text { FCT }\end{array}$ & $\begin{array}{c}\text { FRH, FCT } \\
\text { and } \\
\text { Ice-albedo } \\
\text { feedback }\end{array}$ \\
\hline $\begin{array}{l}\text { Manabe and Wetherald } \\
\text { (1967) }\end{array}$ & 65 & $129^{*}$ & & \\
\hline Ramanathan (1976) & & 121 & 197 & \\
\hline Wang and Lacis (1979) & & 110 & 135 & $188^{* *}$ \\
\hline
\end{tabular}

* Wetherald and Manabe (1975) obtained $\beta=114 \mathrm{~K}$ with a more accurate radiation scheme.

** See Wang and Stone (1980).

providing first-order estimates for climatic effects associated with perturbations of atmospheric trace constituents.

To study the radiative effect of $\mathrm{O}_{3}$ depletion in the lower stratosphere and the greenhouse effect due to carbon tetrafluoride, we adopt the model developed by Wang et al. (1976) and Wang and Lacis (1979). In this globally averaged model the atmosphere is allowed to reach equilibrium with a timemarching computational procedure. For the assumed atmospheric compositions, global mean surface albedo and initial temperature distribution at time $t$, the local radiative heating and cooling rates for solar and thermal radiation are computed at each altitude. The net heating rate is then used to determine the local temperature at time $t+\Delta t$. At any altitude where the computed temperature lapse rate is steeper than a preassigned value, equal to $6.5 \mathrm{~K} \mathrm{~km}^{-1}$ in the standard model, it is assumed that convection occurs. The vertical energy flux is such as to establish the preassigned lapse rate. Iteration with the timemarching procedure is continued until energy balance is achieved at each level in the atmosphere. Despite its simplicity, the model includes a few important feedback mechanisms. In the following we discuss first the effect of the feedback on the perturbation calculations.

A convenient measure of the influence of the feed-

TABLE 1b. Comparison of solar and thermal sensitivity parameters.

\begin{tabular}{|c|c|c|c|}
\hline Model & & $\begin{array}{c}\frac{d F}{d T_{s}} \\
\left(\mathrm{~W} \mathrm{~m}^{-2}\right)\end{array}$ & $\begin{array}{l}\frac{S_{0}}{4} \frac{d \alpha}{d T_{s}} \\
\left(\mathrm{~W} \mathrm{~m}^{-2}\right)\end{array}$ \\
\hline Ramanathan (1976) & $\left\{\begin{array}{l}\mathrm{FCT} \\
\mathrm{FCA}\end{array}\right.$ & $\begin{array}{l}1.37 \\
2.25\end{array}$ & $\begin{array}{l}-0.24 \\
-0.24\end{array}$ \\
\hline Wang and Lacis (1979) & $\left\{\begin{array}{l}\text { FCT } \\
\text { FCA }\end{array}\right.$ & $\begin{array}{l}1.70 \\
2.39\end{array}$ & $\begin{array}{r}0.04 \\
-0.24\end{array}$ \\
\hline
\end{tabular}

back on the sensitivity of the global climate model is the parameter defined as (cf. Schneider and Dickinson, 1974)

$$
\beta=S_{0} \frac{d T_{s}}{d S},
$$

where $S$ is the solar constant and $S_{0}=1365 \mathrm{~W} \mathrm{~m}^{-2}$ is the present value of $S ; T_{s}$ is the computed global mean surface temperature. Table 1a shows the effect of the feedbacks on the sensitivity of the different models. Manabe and Wetherald (1967) were the first to assume that the relative humidity of the atmosphere would remain fixed during climate perturbation studies. Thus, if the temperature increases in a perturbation calculation, the absolute humidity also increases, causing a substantial positive feedback of $\sim 2.0$. More elaborate radiative calculations (Wang et al., 1976; Wang and Lacis, 1979) confirm this, with a smaller feedback factor of $\sim 1.6$. Because of the model's inability to predict cloudiness feedback effects, it is generally assumed either fixed cloud altitude (FCA) or fixed cloud temperature (FCT) for perturbation calculations. Wang and Lacis (1979) have shown that the value for $\beta$ obtained under the latter assumption is about a factor of 1.2 larger than that obtained under the former assumption. On the other hand, Ramanathan (1976) obtained a much larger value, 1.6. To see why, we rewrite Eq. (1) so that $\beta$ is expressed in terms of the thermal sensitivity parameter $d F / d T_{s}$ and the solar sensitivity parameter $\left(S_{0} / 4\right)\left(d \alpha / d T_{s}\right)$ als

$$
\beta=\frac{F}{\frac{d F}{d T_{s}}+\frac{S_{0}}{4} \frac{d \alpha}{d T_{s}}},
$$

where $\alpha$ is the planetary albedo and $F$ the outgoing thermal flux at the top of the atmosphere. This equation is derived directly from the condition that $S_{0}(1-\alpha)=4 F$ at the top of the atmosphere. Values of the thermal and solar sensitivity parameters for the two models are given in Table 1b. Most of the contribution to $\beta$ comes from the thermal sensitivity parameters. For the FCA parameterization, the two models agree well. However, the models differ significantly for the FCT parameterization. This is caused primarily by the different treatment of clouds in the two models (Ramanathan, personal communication). For example, Wang et al. (1976) and Wang and Lacis (1979) used realistic cloud spectral data for radiative transfer calculations while Ramanathan assumed gray clouds in the solar region and black clouds in the thermal region. Furthermore, Wang and Lacis' model allows both cloud top and base altitudes to move if the surface temperature is perturbed. In this treatment, the solar sensitivity parameter will have a small positive value instead of a negative value of 0.24 found for 
the FCA parameterization. The reason is that both the cloud altitude and atmospheric water vapor amount increase as surface temperature increases. But these changes have a partially compensating effect on the planetary albedo with the former increasing the albedo and the latter decreasing it. The net effect yields a small positive solar sensitivity parameter for the FCT parameterization. Overall, in Wang and Lacis' model both thermal and solar sensitivity parameters contribute to smaller model sensitivity value $\beta$. In fact, this result also partially explains the large difference found between the two models for the study of the radiative effect of a factor of 20 increase in the atmospheric chlorofluoromethanes (CFM's) (cf. Ramanathan, 1975; Wang et al., 1976). After including the band strength temperature dependence of the CFM's ${ }^{2}$ in the Wang and Lacis' model, we find that the greenhouse effect of CFM's is $0.69 \mathrm{~K}$ which is larger than previously reported $0.56 \mathrm{~K}$ (see Wang et al., 1976). However, this value is still smaller than $0.9 \mathrm{~K}$ computed by Ramanathan (1975), primarily because of the differences in model sensitivity. The ice-albedo feedback can also be readily incorporated into the model with a procedure described by Wang and Stone (1980). The net result is to further enhance the temperature perturbation by a factor of 1.4 (see Table 1a).

All feedback mechanisms we have discussed so far enhance the perturbation calculations. Recently, it has been shown that the radiative perturbation can be reduced by $-30 \%$ if the moist adiabatic lapse rate is used instead of a constant $6.5 \mathrm{~K} \mathrm{~km}^{-1}$ lapse rate (Wang and Lacis, 1979). In addition, the important cloud amount feedback is neglected in all the models. Nevertheless, they must wait for better understanding of the physical processes which control the feedbacks. In the present study, unless otherwise stated, we assume fixed relative humidity, fixed cloud altitude and no ice-albedo feedback in all present computations. The values for $\Delta T_{s}$ we calculated should be multiplied by a factor 2.0 if we make the assumption of fixed cloud temperature (Cess, 1975) with ice-albedo feedback.

\section{Radiative effects due to ozone depletion in the stratosphere}

It is worthwhile first to examine the role which ozone plays in determining the earth's atmospheric thermal structure. Ozone has important absorption bands in the ultraviolet, visible and infrared. Absorption of solar radiation in the Hartley, Huggins and Chappuis bands provides a major source

\footnotetext{
${ }^{2}$ Ramanathan (personal communication) points out that the CFM band intensities employed in Wang et al. (1976) are measured at a temperature $T=300 \mathrm{~K}$. Hence, calculations that neglect the temperature dependence underestimate the greenhouse effect.
}

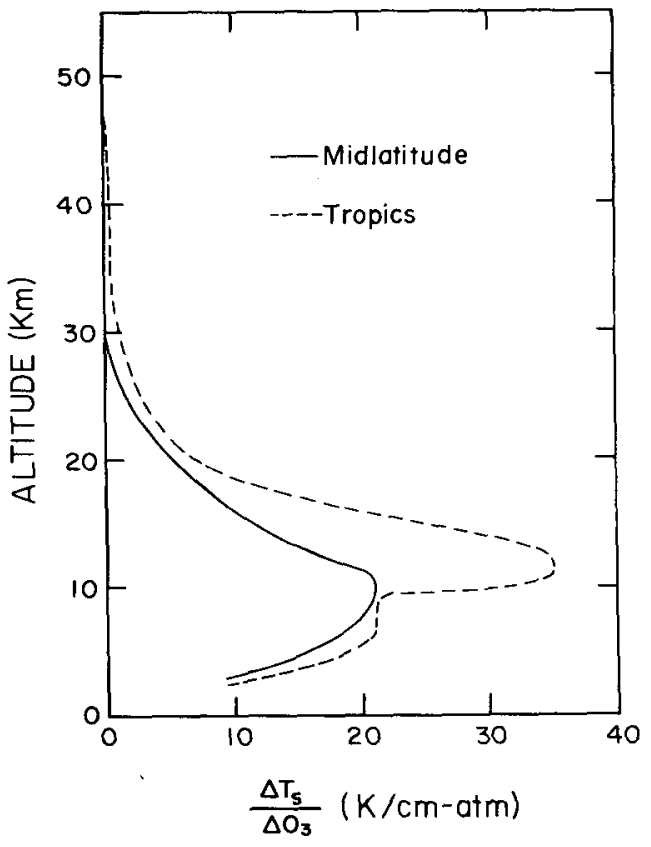

FIG. 1. Sensitivity of surface temperature change $\Delta T_{x}$ to changes in $\mathrm{O}_{3}$ concentration for midlatitude and tropical atmospheres. The curves are obtained by comparing the surface temperature $T_{s}$ in a standaird run with ones in which $50 \%$ of the $\mathrm{O}_{3}$ has been removed from selected narrow altitude ranges. $\Delta \mathrm{O}_{3}$ refers to local $\mathrm{O}_{3}$ changes (cm-atm).

of heating to the middle and upper stratosphere. In the infrared, two strong bands at 9.6 and $14 \mu \mathrm{m}$ serve to cool the upper atmosphere and to provide a greenhouse effect for the lower atmosphere. Using our model, we have calculated the separate solar and thermal effects of $\mathrm{O}_{3}$ in determining the surface temperature for a typical midlatitude atmosphere. To do this, we simply exclude the $\mathrm{O}_{3}$ radiative contribution to the thermal cooling and solar heating, respectively, in computing the thermal structure. It is found that compared to the case with both solar and thermal effects included, neglecting the strong thermal greenhouse effect causes the surface temperature to decrease by $2.6 \mathrm{~K}$ while omitting the solar effect warms up the surface by only $0.2 \mathrm{~K}$. The surface temperature is also sensitive to both the vertical distribution and the column abundance of $\mathrm{O}_{3}$ (Manabe and Wetherald, 1967; Ramanathan et al., 1976; Wang and Lacis, 1979).

It has been recognized that chlorofluoromethaneinduced ozone depletion in the stratosphere can lower local temperatures by as much as $10 \mathrm{~K}$ (Ramanathan et al., 1976; Chandra et al., 1978). But the effect on surface temperature due to depletion of stratospheric $\mathrm{O}_{3}$ is much smaller. The reasons will become clear from the following sensitivity analysis. Fig. 1 shows a sensitivity study of the surface temperature as a function of $\mathrm{O}_{3}$ perturbations at various altitudes for a midlatitude and 


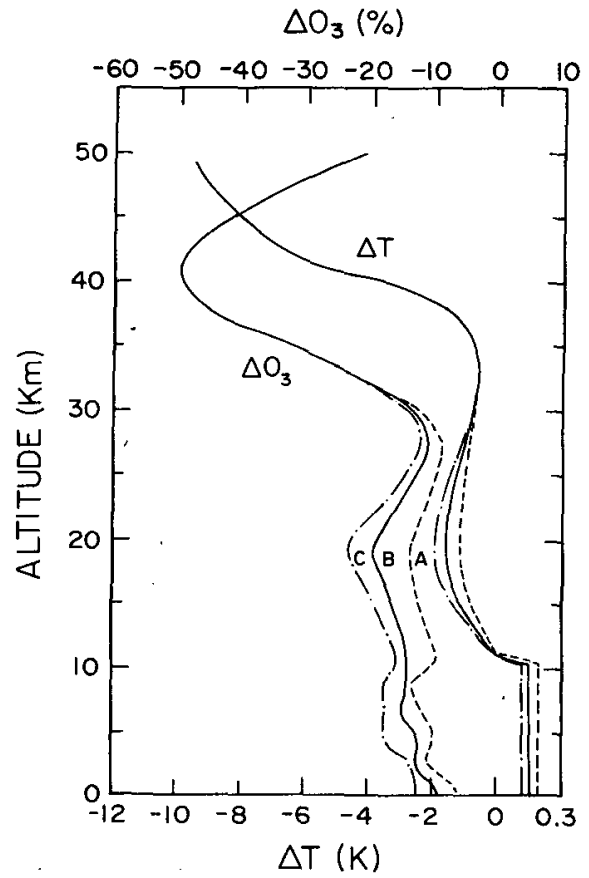

Fig. 2. Perturbations of thermal structure and $\mathrm{O}_{3}$ concentrations at steady state due to continued release of chlorofluoromethanes at 1973 rates. Case $\mathrm{B}$ includes $\mathrm{O}_{3}$ destruction due to the $\mathrm{ClONO}_{2}$ cycle. Case $\mathrm{C}$ includes both the $\mathrm{ClONO}_{2}$ and the $\mathrm{BrO}-\mathrm{ClO}$ cycles. Case A does not include either of the two new cycles. Note that the temperature scales for $\Delta T>0$ and $\Delta T<0$ are different.

a tropical atmosphere. The graph is obtained by comparing the surface temperature $T_{s}$ in a standard run with ones in which $50 \% \mathrm{O}_{3}$ has been removed from selected narrow altitude ranges. In general, the surface temperature is more sensitive to changes in $\mathrm{O}_{3}$ concentration in the tropics because the tropical atmosphere has a higher surface temperature and a smaller column $\mathrm{O}_{3}$ amount compared to the midlatitude atmosphere. Both factors contribute to larger greenhouse effect. In subsequent computations, we choose the midlatitude atmosphere as representative of a globally averaged model. It is clear that on a per molecule basis, ozone changes in the lower stratosphere are most effective in causing a surface temperature change. These results indicate that large perturbations in the $\mathrm{O}_{3}$ profile might affect the surface temperature. For this purpose, we will first study the effect of $\mathrm{O}_{3}$ depletion in the atmosphere caused by increases of $\mathrm{CFCl}_{3}$ and $\mathrm{CF}_{2} \mathrm{Cl}_{2}$.

The present day concentrations of $\mathrm{CFCl}_{3}$ and $\mathrm{CF}_{2} \mathrm{Cl}_{2}$ in the atmosphere are taken to be 0.1 and $0.2 \mathrm{ppbv}$, respectively (NASA, 1977). To examine the effect due to increases in chlorofluoromethanes, we assume that $\mathrm{CFCl}_{3}$ and $\mathrm{CF}_{2} \mathrm{Cl}_{2}$ are continually released at 1973 rates. At steady-state ( $\sim$ year 2030), the atmosphere would contain $\sim 0.8$ and $2.3 \mathrm{ppbv}$ of
$\mathrm{CFCl}_{3}$ and $\mathrm{CF}_{2} \mathrm{Cl}_{2}$, respectively. The greenhouse effect associated with such increases in chlorofluoromethane concentrations is $0.32 \mathrm{~K}$. Using our one-dimensional photochemical model with the set of photochemical reactions recommended by NASA (1977), the perturbed $\mathrm{O}_{3}$ profile is calculated and given in Fig. 2 (curve A): Our results are similar to those obtained by previous workers (Chang, 1976; Logan et al., 1978). The total column ozone reduction for this case is $15 \%$.

Curve $B$ represents an update of the photochemical model by including the following catalytic cycle for ozone destruction (Barker et al., 1979)

$$
\begin{aligned}
\mathrm{ClO}+\mathrm{NO}_{2} & \rightarrow \mathrm{ClONO} \\
\mathrm{ClONO}_{2}+h \nu & \rightarrow \mathrm{Cl}+\mathrm{NO}_{3} \\
\mathrm{NO}_{3}+h \nu & \rightarrow \mathrm{NO}+\mathrm{O}_{2} \\
\mathrm{NO}+\mathrm{O}_{3} & \rightarrow \mathrm{NO}+\mathrm{O}_{2} \\
\mathrm{Cl}+\mathrm{O}_{3} & \rightarrow \mathrm{ClO}+\mathrm{O}_{2} \\
\hline \mathrm{Net} \quad & 2 \mathrm{O}_{3} \rightarrow 3 \mathrm{O}_{2} .
\end{aligned}
$$

The total column ozone reduction is $18 \%$. Compared to curve $\mathrm{A}$, the $\mathrm{O}_{3}$ depletions in the lower stratosphere are increased by $40 \%$. Curve $C$ represents the results obtained by including the effects of bromine in addition to the ClONO: cycle (Yung et al., 1980). The main catalytic cycle for $\mathrm{O}_{3}$ depletion is

$$
\text { Net } \quad \begin{aligned}
\mathrm{BrO}+\mathrm{ClO} & \rightarrow \mathrm{Br}+\mathrm{Cl}+\mathrm{O}_{2} \\
\mathrm{Br}+\mathrm{O}_{3} & \rightarrow \mathrm{BrO}+\mathrm{O}_{2} \\
\mathrm{Cl}+\mathrm{O}_{3} & \rightarrow \mathrm{ClO}+\mathrm{O}_{2} \\
\hline \mathrm{O}_{3} & \rightarrow 3 \mathrm{O}_{2} .
\end{aligned}
$$

The inclusion of these two additional cycles results in a significant reduction of $\mathrm{O}_{3}$ in the lower stratosphere while the total column reduction is $-20 \%$. Fig. 2 also shows the changes in the thermal profile $\Delta T$ for the three cases. When taking into account both the effects of chlorofluoromethanes and ozone depletions as calculated by curve $C$, the net effect on the surface temperature is small, as summarized in Table 2 . The greenhouse effects due to

TABLE 2. The change in surface temperature $\Delta T_{s}$ due to the presence of chlorofluoromethanes (CFM's) at steady state with and without feedback due to ozone perturbations as described in Fig. 2. All values for $\Delta T_{s}$ were computed under the assumptions of fixed relative humidity, fixed cloud altitude and no ice-albedo feedback. For the more realistic assumption of fixed cloud temperature with ice-albedo feedback, each number must be multiplied by a factor 2 .

\begin{tabular}{ll}
\hline \multicolumn{1}{c}{ Assumptions } & $\Delta T_{s}(\mathrm{~K})$ \\
\hline CFM's alone & 0.32 \\
CFM's + curve A* & 0.21 \\
CFM's + curve B* & 0.15 \\
CFM's + curve C* & 0.12 \\
\hline
\end{tabular}

* The curves refer to ozone perturbations in Fig. 2. 
bromine compounds such as $\mathrm{CF}_{3} \mathrm{Br}$ are found to be small for concentrations $<1 \times 10^{-10}$ (present concentration $\sim 10^{-11}$ ).

\section{Greenhouse effect of carbon tetrafluoride}

Carbon tetrafluoride has recently been detected in the atmosphere, (Rasmussen et al., 1979). The mean concentration is about $60 \mathrm{pptv}$, a value that is comparable to the present day concentration of $\mathrm{CFCl}_{3}$ and $\mathrm{CF}_{2} \mathrm{Cl}_{2} . \mathrm{CF}_{4}$ is almost inert in the atmosphere; Cicerone (1979) estimated a lifetime exceeding 10000 years, and it is unlikely that the lifetime can be shorter than 1000 years. While the exact nature of the sources of $\mathrm{CF}_{4}$ are highly uncertain, it is clear that its production is related to some industrial processes. Possible major sources are associated with aluminum refining and steelmaking (Cicerone, 1979; Rasmussen et al., 1979). It should be noted that both these processes depend upon the availability of non-renewable resources. According to Meadows et al. (1974), reserves of high grade aluminum and iron ores could be exhausted by the years 2020 and 2045, assuming average growth rates of 5.5 and $1.8 \%$ per year, respectively. Based on these projections, we have estimated the maximum concentrations of $\mathrm{CF}_{4}$ to be 0.3 and $2.7 \mathrm{ppbv}$, respectively. ${ }^{3}$ This has been done by assuming that the present $\mathrm{CF}_{4}$ abundance is derived from the integrated past productions of aluminum or steel and then multiplied by the fractional amount of ore not yet mined. We have also made the simplistic assumption that the quantum yield of $\mathrm{CF}_{4}$ in future industrial production of aluminum and steel remains the same as today's.

The infrared spectrum of $\mathrm{CF}_{4}$ has been measured from $2-33 \mu \mathrm{m}$ by Woltz and Nielsen (1952). Altogether six bands were observed in this region. The one which contributes most to the greenhouse effect is the $7.8 \mu \mathrm{m} \nu_{3}$ band (centered at $1282.6 \mathrm{~cm}^{-1}$ ) simply because it is located inside the window region and has the largest band intensity. The other bands contribute at most a few percent to the total greenhouse effect. Levin and Lewis (1970) studied the $\nu_{3}$ band and estimated the total intensity to be 4174 $\pm 45 \mathrm{~cm}^{-2} \mathrm{~atm}^{-1}$. Saeki et al. (1976) measured a value of $5934 \pm 170 \mathrm{~cm}^{-2} \mathrm{~atm}^{-1}$ for the same band. More recently, Goldman et al. (1979) observed this band and estimated the intensities for the $Q$ branch and the total band to be 1520 and 4500 $\mathrm{cm}^{-2} \mathrm{~atm}^{-1}$, respectively. This band is extremely narrow with total band width $\sim 5 \mathrm{~cm}^{-1}$. In the present

\footnotetext{
${ }^{3}$ I. Sobolev (personal communication) of Kaiser Aluminum points out that the reserve of high-grade aluminum ore may be more abundant than Meadows et al. (1974) estimate. However, even assuming a $10 \%$ growth rate for the aluminum industry, the $\mathrm{CF}_{4}$ accumulations in the atmosphere would be of the order of a few ppbv in the next 50 years.
}

study, we use the Saeki et al. data to calculate a maximum greenhouse effect. Because $\mathrm{CH}_{4}$ and $\mathrm{N}_{2} \mathrm{O}$ also have absorption bands in the spectral region, we compute the greenhouse effect due to $\mathrm{CF}_{4}$ with and without including the overlapping effect. It is found that the greenhouse effect due to the presence of $\mathrm{CF}_{4}$ in the earth's atmosphere is $0.07 \mathrm{~K}$ (ppbv) ${ }^{-1}$ if the overlapping effect is included. The omission of overlapping effect increases the greenhouse effect to $0.12 \mathrm{~K}(\mathrm{ppbv})^{-1}$. In these computations, we have employed the optical thin (weak line) approximation (Goody, 1964). Because of the extremely narrow band width of the $\nu_{3}$ band, this approximation will not be valid for concentrations $>1$ ppbv. However, the greenhouse effect $(\mathrm{K})$ due to higher concentrations of $\mathrm{CF}_{4}$ can be approximately expressed as

$$
\Delta T_{s}=0.07\left[\frac{\mathrm{CF}_{4}}{\left(\mathrm{CF}_{4}\right)_{0}}\right]^{1 / 2},
$$

where $\left(\mathrm{CF}_{4}\right)_{0}=1 \mathrm{ppbv}$.

\section{Conclusions}

We have shown that there could be strong radiative effects associated with ozone perturbations in the lower stratosphere. Results from an updated photochemical model (Yung et al., 1980) suggest that $\mathrm{O}_{3}$ depletions in the lower stratosphere could be somewhat larger than predicted by previous models. This raises the interesting possibility of a substantial cooling of the troposphere. However, we must emphasize that our results critically depend on the detailed photochemistry for the lower stratosphere, which is subject to a range of uncertainties, as discussed by Yung et al. In contrast, the calculations for greenhouse effects of the halogenated methanes involve fewer assumptions and, hence, depend relatively less on the detailed modeling of the atmosphere. Even so, the region of upper troposphere and lower stratosphere remains to be the most complicated region to model as well as the most crucial region for troposphere climate studies. Further studies should address the problem with coupled dynamics, radiation and photochemistry in this region.

The most serious problem with $\mathrm{CF}_{4}$ is its extremely long lifetime and, hence, its potential for accumulation in the atmosphere. At levels $\sim 1$ ppbv the greenhouse effect becomes marginally important. If the primary source of $\mathrm{CF}_{4}$ is derived from the aluminum and steel industry our simple scaling argument suggests that the greenhouse effect will not reach catastrophic proportions in the near future. Hence, it is important to make definitive identification of the origin of atmospheric $\mathrm{CF}_{4}$, its growth rate, and the quantum yield of $\mathrm{CF}_{4}$ associated with various industrial processes. 
Acknowledgment. We thank N. D. Sze, R. T. Watson, A. Goldman, D. G. Murcray and J. E. Hansen for useful discussion, and R. T. Watson, S. P. Sander and A. A. Lacis for permission to use their results prior to publication. During the course of this work, Pinto was supported by NASA Grant NSG 5163 Scope M to Columbia University. Yung's research was supported by NASA Grant NSG 2229 to the California Institute of Technology.

\section{REFERENCES}

Barker, J. L., J. S. Chang, H. E. Davenport and D. M. Golden, 1979: Chlorine-nitrate photolysis at low pressures. Chem. Phys. Lett., 60, 385-390.

Cess, R. D., 1975: Global climate change: an investigation of atmospheric feedback mechanisms. Tellus, 27, 193-198.

Chandra, S., D. M. Butler and R. S. Stolarski, 1978: Effect of temperature coupling on ozone depletion prediction. Geophys. Res. Lett., 5, 199-202.

Chang, J. S., 1976: Halocarbons: Effects on Stratospheric Ozone. National Academy of Sciences, Washington, D.C., 352 pp.

Cicerone, R. J., 1979: Atmospheric carbon tetrafluoride: A nearly inert gas. Science, 206, 59-61.

Goldman, A., D. G. Murcray, F. J. Murcray, G. R. Cook, J. W. Van Allen, F. S. Bonomo and R. D. Blatherwick, 1979: Identification of the $\nu_{3}$ vibration rotation band of $\mathrm{CF}_{4}$ in balloon-borne infrared solar spectra. Geophys. Res. Lett., 6, 609-612.

Goody, R. M., 1964: Atmospheric Radiation: I. Theoretical Basis. Oxford University Press, 436 pp.

Hansen, J. E., W. C. Wang and A. A. Lacis, 1978: Mount Agung eruption provides test of a global climate perturbation. Science, 199, 1065-1068.

Levin, I. W., and T. P. Lewis, 1970: Absolute infrared intensities of $\mathrm{CF}_{4}$. J. Chem. Phys., 52, 1608-1609.

Logan, J. A., M. J. Prather, S. C. Wofsy and M. B. McElroy, 1978: Atmospheric chemistry: Response to human influence. Phil. Trans. Roy. Soc, London, 290, 187-234.
Manabe, S., and R. T. Wetherald, 1967: Thermal equilibrium of the atmosphere with a convective adjustment. J. Atmos. Sci., 24, 241-259.

Meadows, D. L., W. H. Behrens, D. H. Meadc'ws, R. F. Naill, J. Randers and E. K. O. Zahn, 1974: Dynamics of Growth in a Finite World. Wright-Allen Press, 637 pp.

NASA, 1977: Chlorofluoromethanes and the Stratosphere, R. D. Hudson, Ed. Ref. Publ. 1010, 266 pp.

Ramanathan, V., 1975: Greenhouse effect due to chlorofluorocarbons: Climatic implications. Science, 190, 50-52.

- - 1976: Radiative transfer within the earth's troposphere and stratosphere: A simplified radiative-convective model. J. Atmos. Sci., 33, 1330-1346.

—, L. B. Callis and R. E. Boughnev, 1976: Sensitivity of surface temperature to perturbations in the stratospheric concentration of ozone and nitrogen dioxidie. J. Atmos. Sci., 33, $1092-1112$.

Rasmussen, R. A., S. A. Penkett and N. Prosser, 1979: Measurement of carbon tetrafluoride in the atmosphere. Nature, 277, 549-551.

Saeki, S., M. Mizuno and S. Kondo, 1976: Intrared absorption intensities of methane and fluoromethanes. Spectrochim. Acta, 32A, 403-413.

Schneider, S. H., and R. E. Dickinson, 1974: Climate modeling. Rev. Geophys. Space Phys., 12, 447-493.

Wang, W.-C., and A. A. Lacis, 1979: A one-dimensional radiative-convective model of the earth's atmosphere for climate applications. In preparation.

$\longrightarrow$, and P. H. Stone, 1980: Effect of ice-altedo feedback on global sensitivity in a one-dimensional radiative-convective climate model. J. Atmos. Sci., 37 (in pres:).

- , Y. L. Yung, A. A. Lacis, T. Mo and J. E. Hansen, 1976: Greenhouse effects due to man-made perturbations of trace gases. Science, 194, 685-690.

Wetherald, R. T., and S. Manabe, 1975: The effects of changing the solar constant on the climate of a general circulation model. J. Atmos. Sci., 32, 2044-2059.

Woltz, P. J. H., and A. H. Nielsen, 1952: The infrared spectra of $\mathrm{CF}_{4}$ and $\mathrm{GeF}_{4}$. J. Chem. Phys., 20, 30\%-312.

Yung, Y. L., J. P. Pinto, R. T. Watson and S. P. Sander, 1980: Atmospheric bromine and ozone perturbations in the lower stratosphere. J. Atmos. Sci., 37, (Feb. issue). 